\title{
Monitoramento protéico em rebanhos de vacas leiteiras em Sergipe
}

\author{
Monitoring protein in herd of dairy cows in Sergipe
}

\author{
Flávia Rejane de Andrade Lira'; Veronaldo Souza de Oliveira²; \\ Gladston Rafael de Arruda Santos'; ${ }^{2}$ Monica Alixandrina da Silva ${ }^{3}$; \\ Aline Guimarães de Oliveira ${ }^{4 *}$; Julianne Santiago Silva Goveia ${ }^{4}$
}

\section{Resumo}

O objetivo dessa pesquisa foi avaliar a concentração de nitrogênio ureico no plasma (NUP) em diferentes rebanhos leiteiros, de modo a obter um diagnóstico dos níveis de aproveitamento proteico dietético de vacas em lactação e relacionar esses níveis com aspectos produtivos e econômicos. O experimento foi conduzido em 25 propriedades rurais com exploração de bovinocultura leiteira, no município de Nossa Senhora da Glória - SE. Foram realizadas coletas de sangue em cinco vacas por propriedade, a cada 30 dias, em um período de três meses para determinação do NUP. Em seguida, foram selecionadas 10 propriedades, entre as 25 avaliadas, que apresentavam maior controle zootécnico, para analisar possíveis associações do NUP com parâmetros nutricionais, produtivos e reprodutivos, além de avaliar o comprometimento da renda do leite (CRL) com a suplementação concentrada. O delineamento experimental foi o inteiramente casualizado, com parcelas subdivididas no tempo. Foram obtidas variações de NUP entre 6,97 e 29,2 mg/dL $(\mathrm{P}<0,05)$ e média geral de $15,46 \mathrm{mg} / \mathrm{dL}$ entre as propriedades. Destas, apenas $37,33 \%$ apresentaram NUP dentro dos padrões, sendo verificado que níveis crescentes de proteína bruta $(\mathrm{PB})$ na dieta resultaram na elevação dos valores de NUP e redução da eficiência reprodutiva. Foi observado um comprometimento médio de $38,17 \%$ da renda do leite (CRL), com a utilização de concentrado, entre as propriedades. Nas condições desse trabalho, conclui-se que houve grande variação nos níveis de NUP que apresentaram desde valores baixos, indicando possível falha no manejo nutricional a níveis acima dos preconizados, sugerindo um excesso de proteína oferecido aos animais ou desbalanço nutricional na relação proteína/energia. Esses dados demonstram a necessidade de uma assistência técnica local orientando para um melhor manejo nutricional desses rebanhos.

Palavras-chave: Bovino, nitrogênio ureico no plasma, reprodução

\begin{abstract}
The object this research was to evaluate the urea plasma urea nitrogen (PUN) in different dairy herds in order to obtain a diagnosis of levels of dietary protein utilization of lactating cows and to relate these levels with economic and productive aspects. The experiment was conducted in 25 rural properties with the exploitation of dairy cattle in the municipality of Nossa Senhora da Glória - SE. Blood samples were collections in five cows per properties, every 30 days, over a period of three months to determining of the NUP. Then, were selected 10 properties, among the 25 evaluated, which
\end{abstract}

\footnotetext{
${ }^{1}$ Médica Veterinária do Instituto Federal de Educação, Ciência e Tecnologia de Sergipe, IFS, Campus São Cristóvão, Povoado Quissamã, São Cristóvão, SE. E-mail: fraliravet@gmail.com

${ }^{2}$ Profs. do Dept ${ }^{\mathrm{o}}$ de Zootecnia, UFS, São Cristóvão, SE. E-mail: veronaldo@terra.com.br; gladstonrafael@ufs.br

${ }^{3}$ Prof $^{a}$ do Instituto Federal de Educação, Ciência e Tecnologia de Sergipe, IFS, Campus São Cristóvão, Povoado Quissamã, São Cristóvão, SE. E-mail: monica.alixandrina@ifs.edu.br

${ }^{4}$ Discentes de Mestrado em Zootecnia, Universidade Federal de Sergipe, UFS, São Cristóvão, SE. E-mail: alinegzoo@yahoo.com. br; jussgoveia@yahoo.com.br

* Autor para correspondência
} 
featured greater control to analyze zootechnical, to analyze possible PUN associations with nutritional, productive and reproductive parameters, as well as evaluating the milk income's commitment (CRL) with concentrated supplementation. The experimental design was completely randomized split plot in time. Were obtained variations of PUN between 6.97 and $29.2 \mathrm{mg} / \mathrm{dL}(\mathrm{P}<0.05)$ and overall average of $15.46 \mathrm{mg} / \mathrm{dL}$ between the properties. Of these, only $37.33 \%$ presented within the standards, being PUN found that increasing levels of crude protein $(\mathrm{CP})$ in the diet resulted in the elevation of the NUP values and reduced reproductive efficiency. It was observed an average commitment of $38.17 \%$ of income from milk (CRL), with the use of concentrated, between the properties. Under the conditions of this research, there was wide variation in the levels of PUN who had since low values, indicating a possible fault in the nutritional management to levels above those recommended, suggesting an excess of protein offered to the animals or nutritional imbalance in the ratio of protein/energy. These data demonstrate the need for a local service guiding for better nutritional management of these herds.

Key words: Cattle, plasma urea nitrogen, reproduction

\section{Introdução}

A bovinocultura de leite representa uma atividade de grande importância socioeconômica no Estado de Sergipe, concentrando-se principalmente em sete municípios (Nossa Senhora da Glória, Monte Alegre, Canindé do São Francisco, Poço Redondo, Porto da Folha, Gararu e Nossa Senhora de Lourdes) (SEAGRI, 2008). Estes municípios formam um território conhecido como Alto Sertão Sergipano, o qual é responsável por mais de $50 \%$ da produção de leite do Estado e movimentação da economia da região. No ano 2010, Sergipe apresentou 220.889 vacas ordenhadas com produção de 296,6 milhões de litros de leite, representando uma produtividade em torno de 1343 litros/vaca/ano e gerando lucros em torno de 203,1 milhões de reais (IBGE, 2010).

A elaboração de dietas que atendam as exigências dos animais, em cada fase de produção, é uma dificuldade enfrentada principalmente pelos pequenos e médios produtores. Isto resulta, muitas vezes, em formulações inapropriadas de dietas com excesso ou escassez de proteínas e desbalanceamento de outros componentes como energia, podendo influenciar negativamente no aproveitamento da proteína ingerida e produzida pela microbiota do rúmen, elevando o custo de produção com a atividade e reduzindo índices de eficiência produtiva.

É de suma importância o fornecimento de proteína em quantidade e qualidade, observando suas relações com os demais ingredientes dietéticos, pois a proteína é o segundo nutriente limitante em dietas para ruminantes e também pode ser considerado o ingrediente mais oneroso na formulação de dietas para vacas leiteiras, devido ao elevado custo de fontes tradicionais, como o farelo de soja (PINA et al., 2006).

Os ruminantes suprem suas exigências nutricionais de aminoácidos (aa) através da ingestão de proteínas não degradáveis no rúmen (PNDR), da síntese de proteína microbiana no rúmen e, em menor quantidade, pela contribuição das células de descamação da parede ruminal (NRC, 2001). A proteína dietética, dependendo de sua degradabilidade ruminal, é absorvida no intestino delgado sob a forma de aa ou degradada pelos microorganismos ruminais para a síntese de proteína microbiana (MERCHEN; BOURQUIN, 1994). No processo de degradação pelos microrganismos ruminais, a proteína é convertida principalmente em amônia $\left(\mathrm{NH}_{3}\right)$, utilizada pelos microrganismos para produzir seus próprios aminoácidos e proteínas. $\mathrm{O}$ restante da amônia é absorvida e levada até o fígado, onde é convertida em uréia. A uréia é transportada por todo o organismo e é excretada através do leite, urina e saliva. Além disso, a amônia pode chegar até o útero e, quando em altos níveis, pode afetar os processos reprodutivos (BERCHIELLI; PIRES; OLIVEIRA, 2006). Assim, o excesso de proteína na dieta deve ser evitado para proporcionar aos animais uma ótima fermentação ruminal, manter sua fertilidade e produção de leite em níveis adequados. 
Segundo Hristov, Etter e Ropp (2004), vacas leiteiras de baixa produção que recebem dietas com excesso de proteína degradável no rúmen, apresentam ineficiência de síntese de proteína microbiana e perdas substanciais de nitrogênio $(\mathrm{N})$ através da excreção urinária. Além disso, tornase menos eficiente a utilização de amônia ruminal para a síntese de aminoácidos para a produção de proteína do leite.

A uréia circulante pode ser mensurada através do nitrogênio ureico no plasma (NUP), que representa $\mathrm{N}$ não aproveitado pelo animal, refletindo seu estado nutricional proteico atual, indicando também o equilíbrioruminal entre Neenergia(VASCONCELOS et al., 2010). De acordo com Lucci et al. (2006), o NUP apresenta alta correlação com nitrogênio ureico no leite (NUL), porém apresenta a vantagem sobre este, em poder ser utilizado em animais não lactantes e em outras categorias animais, além da facilidade da realização do exame em qualquer laboratório de análise clínica humana ou animal, simplificando seu uso como rotina por profissionais da área de assistência técnica rural.

Dessa forma, o monitoramento da concentração de NUP torna-se uma importante ferramenta para avaliar a eficiência do aproveitamento da proteína na dieta de vacas em lactação e sua determinação pode auxiliar no ajuste e implantação de estratégias de alimentação, aumentando a eficiência econômica e minimizando o impacto ambiental da atividade (JONKER; KOHN, 2002).

O objetivo dessa pesquisa foi avaliar a concentração de nitrogênio ureico no plasma (NUP) de diferentes rebanhos leiteiros, de modo a obter um diagnóstico dos níveis de aproveitamento proteico dietético de vacas em lactação e relacionar esses níveis com aspectos produtivos.

\section{Material e Métodos}

O trabalho foi realizado no município de Nossa Senhora da Glória, localizado a 126 km de Aracaju-
SE (latitude Sul: $10^{\circ} 12^{\prime} 57^{\prime \prime}$ e longitude: $\left.37^{\circ} 25^{\prime} 09^{\prime \prime}\right)$ e altitude de $300 \mathrm{~m}$. O índice pluviométrico médio anual é de $853,7 \mathrm{~mm}$ e temperatura média anual de $24,2{ }^{\circ} \mathrm{C}$. O período chuvoso concentra-se entre os meses de março e agosto, apresentando clima do tipo BSsh, conforme classificação de Köppen (SIRHSE, 2010).

O experimento foi conduzido em 25 propriedades rurais com exploração de bovinocultura leiteira, durante os meses de setembro, outubro e novembro de 2010. Foram observados índices pluviométricos de 60,$8 ; 32$ e $0 \mathrm{~mm}$ nos respectivos meses da pesquisa. Foram coletadas informações sobre o manejo produtivo, reprodutivo e alimentar realizado em cada propriedade, através de um questionário abordando data de parição, número de partos, produção de leite, alimentação e custos com a suplementação concentrada.

Os animais utilizados no experimento apresentavam genótipo Holandês igual ou acima de 15/16, sendo mantidos a pasto recebendo suplementações diversas entre as propriedades. A composição dos suplementos oferecidos aos animais encontra-se na tabela 1 e foi estimada por meio das tabelas brasileiras de composição de alimentos para bovinos de autoria de Valadares Filho et al. (2006).

Após levantamento da quantidade média de vacas ordenhadas nas propriedades, foram escolhidas aleatoriamente cinco vacas em lactação, por propriedade, com período de lactação variando entre 45 a 120 dias, pluríparas, com escore corporal entre 3 e 3,5 (escala de 1 a 5) e produção acima de 10 litros de leite/dia. Os animais recebiam concentrado como parte da dieta e o manejo nutricional, produtivo e reprodutivo não foram alterados, permanecendo os mesmos normalmente realizados, evitando assim, qualquer interferência externa que pudesse provocar alterações nos parâmetros avaliados, para que os dados obtidos refletissem fielmente o manejo realizado no rebanho de cada propriedade.

Foram realizadas coletas de sangue a cada 30 dias, totalizando três coletas em cada uma das 
cinco vacas selecionadas de cada propriedade, para determinação da concentração de NUP dos animais. Aproximadamente quatro horas após o fornecimento da dieta no cocho, amostras de sangue foram obtidas através de punção da veia jugular, utilizando agulhas, coletores e tubos vacutainer de $10 \mathrm{~mL}$ com anticoagulante (heparina), estéreis e identificados previamente. Em seguida, as amostras foram centrifugadas a $5.000 \mathrm{rpm}$ durante 15 minutos para obtenção do plasma. Este foi transferido para recipientes plásticos tipo eppendorf de $2 \mathrm{~mL}$, estéreis e previamente identificados, sendo armazenados em freezer a $-20^{\circ} \mathrm{C}$.

Tabela 1. Composição e custos dos Alimentos fornecidos nas propriedades.

\begin{tabular}{ccccccc}
\hline \multirow{2}{*}{ Alimentos } & \multicolumn{7}{c}{ Composição* } \\
\cline { 2 - 6 } & MS (\%) & NDT (\%) & PB (\%) & PDR (\%) & PNDR (\%) & $\mathrm{Kg} / \mathrm{R} \$^{* *}$ \\
\hline Volumoso & & & & & & \\
Silagem de Milho & 30,92 & 64,27 & 7,26 & 4,45 & 2,81 & 0,02 \\
Palma Forrageira & 10,20 & 65,04 & 4,95 & 2,97 & 1,98 & 0,06 \\
Rolão de milho & 90,14 & 68,00 & 2,90 & 1,16 & 1,74 & 0,46 \\
Concentrado & & & & & & \\
Milho, Fubáy & 87,64 & 87,24 & 9,11 & 3,75 & 5,35 & 0,66 \\
Soja. Farelo & 88,61 & 81,54 & 48,78 & 31,99 & 16,78 & 1,10 \\
Trigo, Farelo & 88,01 & 72,43 & 16,63 & 13,30 & 3,30 & 0,70 \\
Arroz, Farelo & 88,71 & 83,64 & 13,95 & 10,32 & 3,63 & 0,68 \\
Resíduo de Cervejaria & 20,04 & 66,00 & 26,58 & 14,62 & 11,96 & 0,12 \\
$\quad$ Mineral & 100,00 & & & & & 2,67 \\
Algodão, Caroço & 90,64 & 81,92 & 22,62 & 7,69 & 14,93 & 0,80 \\
Algodão, farelo & 93,00 & 69,75 & 41,66 & 22,92 & 18,75 & 0,80 \\
$\quad$ Ureia & 97,53 & & 281,00 & 281,00 & & 1,52 \\
Refinazil & 87,40 & 80,00 & 23,45 & 16,88 & 6,57 & 0,52 \\
\hline
\end{tabular}

*Fonte: Valadares Filho (2006). MS: matéria seca; NDT: nutrientes digestíveis totais; PB: proteína bruta; PDR: proteína degradável no rúmen; PNDR: proteína não degradável no rúmen.

**Fonte: Mercado local de N. S. Glória (SE), novembro / 2010.

Para a determinação da uréia, o plasma foi descongelado à temperatura ambiente e analisado utilizando o Kit comercial Doles ${ }^{\circledR}$ (Labtest), seguindo as orientações técnicas do fabricante. As leituras das concentrações foram realizadas através do analisador bioquímico semiautomático (Thermoplate) pelo método de ponto final, em laboratório do Departamento de Agronomia da Universidade Federal de Sergipe. As concentrações de nitrogênio obtidas foram multiplicadas por 0,466 para conversão dos valores para nitrogênio ureico no plasma (NUP).

Entre as 25 propriedades analisadas, 10 foram selecionadas, no último mês de coleta, por apresentarem um maior controle zootécnico, reprodutivo e nutricional. Nelas, foram avaliados NUP, peso corporal, escore de condição corporal (ECC), dias de lactação, produção de leite, percentuais de proteína bruta (PB) na dieta, proteína degradável no rúmen ( $\mathrm{PDR})$, proteína não degradável no rúmen (PNDR), nutrientes digestíveis totais (NDT) e dados reprodutivos como: período de serviço (PS) e taxa de prenhez. Também foram feitas possíveis associações entre os níveis de NUP com os parâmetros avaliados e o comprometimento da renda do leite (CRL) com o fornecimento da suplementação concentrada.

As exigências nutricionais dos animais (Tabela 2) e os teores da dietas em PB, PDR, PNDR e NDT, 
de cada propriedade, foram estimadas nas dietas de acordo com o NRC (2001), observando o período de lactação, número de partos, produção de leite, gordura e período de gestação de cada animal.

Tabela 2. Exigências nutricionais médias estimadas nos rebanhos das 10 propriedades selecionadas, com base no NRC (2001).

\begin{tabular}{crrrrrrrrrr}
\hline \multirow{2}{*}{ Composição** Propriedades } \\
\cline { 2 - 11 } & \multicolumn{1}{c}{1} & \multicolumn{1}{c}{ 2 } & \multicolumn{1}{c}{ 3 } & \multicolumn{1}{c}{5} & \multicolumn{1}{c}{6} & \multicolumn{1}{c}{7} & \multicolumn{1}{c}{8} & 10 \\
\hline PB (\%) & 12,35 & 13,29 & 11,97 & 12,48 & 14,33 & 13,65 & 14,11 & 14,18 & 14,14 & 14,21 \\
PDR (\%) & 7,61 & 8,19 & 7,61 & 7,86 & 8,89 & 8,28 & 8,86 & 8,58 & 8,65 & 8,64 \\
PNDR (\%) & 4,74 & 5,09 & 4,36 & 4,62 & 5,44 & 5,30 & 5,25 & 5,80 & 5,50 & 5,57 \\
NDT(\%) & 63,69 & 65,39 & 64,35 & 63,80 & 67,96 & 66,09 & 68,25 & 67,50 & 66,98 & 67,63 \\
\hline
\end{tabular}

*PB: proteína bruta; PDR: proteína degradável no rúmen; PNDR: proteína não degradável no rúmen; NDT: nutrientes digestíveis totais.

Fonte: Elaboração dos autores.

O delineamento experimental utilizado foi inteiramente casualizado (DIC), em parcelas subdivididas no tempo, onde as 25 propriedades representaram as parcelas, as coletas mensais as subparcelas e as cinco vacas de cada propriedade foram as repetições. Os dados obtidos foram tabulados para análise de variância através do programa estatístico Sisvar $^{\circledR}$ (FERREIRA, 2003), onde as médias foram comparadas através do teste Scott Knott a 5\%.

Os resultados das análises do NUP foram agrupados em quatro classes $(<10,10-16,>16-19$ e $>19 \mathrm{mg} / \mathrm{dL}$ ), onde os valores de $10-16 \mathrm{mg} / \mathrm{dL}$ representam dietas com maior eficiência microbiana e valores acima de $19 \mathrm{mg} / \mathrm{dl}$, estão relacionados a perdas reprodutivas (JONKER; KOHN; ERDMAN, 1999). Os dados obtidos nas 10 propriedades foram comparados entre si e relacionados com o NUP através do teste de Scott Knott a 5\%, sendo os resultados quantitativos, submetidos à análise de regressão.

\section{Resultados e Discussão}

As concentrações de NUP analisadas entre as 25 propriedades apresentaram variações nos três meses de coleta $(\mathrm{P}<0,05)$, obtendo níveis que oscilaram de 6,97 a $24,00 \mathrm{mg} / \mathrm{dL} ; 7,17$ a $29,20 \mathrm{mg} / \mathrm{dL}$ e 7,18 a $25,53 \mathrm{mg} / \mathrm{dL}$ nos meses respectivos (Tabela 3 ). Tais oscilações podem estar relacionadas aos diferentes tipos de manejo e dieta utilizados dentro de cada propriedade e entre cada mês de coleta. Apenas em quatro propriedades não foi observada variação significativa dos níveis de NUP entre os meses de coleta.

Tabela 3. Variação percentual entre as 25 propriedades por níveis de NUP observado nos diferentes meses de coleta.

\begin{tabular}{|c|c|c|c|c|c|c|c|c|c|}
\hline \multirow{3}{*}{ Coleta } & \multirow{3}{*}{$\begin{array}{c}\text { Total de } \\
\text { Propriedades }\end{array}$} & \multicolumn{8}{|c|}{ NUP } \\
\hline & & \multicolumn{2}{|c|}{$<10 \mathrm{mg} / \mathrm{dl}$} & \multicolumn{2}{|c|}{$10-16 \mathrm{mg} / \mathrm{dl}$} & \multicolumn{2}{|c|}{$>16-19 \mathrm{mg} / \mathrm{dl}$} & \multicolumn{2}{|c|}{$>19 \mathrm{mg} / \mathrm{d}$} \\
\hline & & $\mathrm{N}$ & $\%$ & $\mathrm{~N}$ & $\%$ & $\mathrm{~N}$ & $\%$ & $\mathrm{~N}$ & $\%$ \\
\hline Setembro & 25 & 4 & 16 & 11 & 44 & 5 & 20 & 5 & 20 \\
\hline Outubro & 25 & 5 & 20 & 7 & 28 & 3 & 12 & 10 & 40 \\
\hline Novembro & 25 & 6 & 24 & 10 & 40 & 3 & 12 & 6 & 24 \\
\hline
\end{tabular}

Legenda: N - número de propriedades; NUP: nitrogênio ureico no plasma.

Fonte: Elaboração dos autores. 
As variações de NUP obtidas foram transformadas em valores percentuais e agrupadas em quatro classes de NUP em cada mês pesquisado, de acordo com os padrões encontrados na literatura, como o proposto por Jonker, Kohn e Erdman (1999), que definem 10-16 mg/dL como valores aceitáveis. Este agrupamento representa os percentuais de propriedades que obtiveram NUP abaixo, no padrão ou acima dos níveis aceitáveis, inclusive acima de $19 \mathrm{mg} / \mathrm{dL}$ o que, segundo Ferguson, Blanchard e Galligan (1998), poderia estar associado a problemas reprodutivos.

Variações de NUP em fazendas e/ou rebanhos também foram verificadas por Butler, Calaman e Beam (1996); Elrod e Butler (1993), que observaram níveis de NUP entre 8,4 a 27,2 mg/dl, trabalhando com bovinos de leite ou corte. Em condições semiáridas brasileiras, Gomes, Dias e Soto-Blanco (2005), obtiveram teores de NUP variando entre 9 e $22,95 \mathrm{mg} / \mathrm{dL}$ ao realizarem um levantamento do estado nutricional de vacas leiteiras em propriedades do Rio Grande do Norte.

Os dados médios de NUP, em duas propriedades, se mantiveram abaixo de 10-16 mg/dL nas três coletas, considerado como indicativo de um bom manejo nutricional (JONKER; KOHN; ERDMAN, 1999), indicando possível falha no manejo nutricional do rebanho associado à deficiência de PB. Apenas duas propriedades mantiveram a média de NUP, durante os três meses de coleta, próximos a concentração de 10-16 mg/dL. Tal situação deve-se às melhores condições de manejo geral e nutricional dos animais e maior reserva alimentar observado nessas propriedades, onde os produtores já recebiam assistência técnica local há alguns anos.

Níveis acima dos preconizados foram observados em pelo menos uma coleta de 17 propriedades, sugerindo um possível excesso de proteína oferecido aos animais, principalmente pelo uso abusivo do farelo de soja ou do desbalanço nutricional na relação proteína/energia, o qual foi verificado na composição das dietas de algumas propriedades. Esses dados demonstram a grande oscilação na composição das dietas, dentro de cada propriedade, e a necessidade de uma assistência técnica local orientando para um melhor manejo nutricional desses rebanhos.

Entre as médias de NUP por coleta, foram observadas diferenças significativas $(\mathrm{P}<0,05)$ entre o mês de outubro e os meses de setembro e novembro, obtendo-se um valor médio de 15,46 $\mathrm{mg} / \mathrm{dL}$ nas três coletas. Essas diferenças podem ter sido influenciadas pela coleta de outubro ter sido realizada em uma fase de transição na composição das dietas, onde havia uma maior disponibilidade de pastagem no mês de setembro resultante das chuvas ocorridas neste período. Já no mês de outubro, as chuvas diminuíram dando início a um período de escassez de forragem, o qual foi agravado no mês de novembro devido a não ocorrência de chuvas.

A partir do mês de outubro, foram observadas inclusões gradativas de diversos tipos de alimentos na dieta como os volumosos: silagem de milho, rolão de milho, palma forrageira e resíduo de cervejaria; e de fontes proteicas concentradas, tais como: farelo de soja e algodão, normalmente utilizados para suprir as necessidades nutricionais dos animais nos meses mais secos do ano.

Os produtores com menor poder aquisitivo observados nesse estudo, justificaram a grande oscilação nas dietas de seus rebanhos devido à irregularidade na disponibilização de recursos para aquisição da suplementação dos animais no período de estiagem, pois o valor obtido com a venda do leite, geralmente é a principal renda para a manutenção de suas famílias. Tal situação também foi verificada por Carvalho Filho et al. (2000), através de um diagnóstico de sistemas de produção realizado no Município de Nossa Senhora da Glória - SE, que relataram falta de capital de giro e dificuldades dos produtores para utilizar tecnologias para suprir escassez de alimentos nos meses mais secos.

Pode-se observar na tabela 3 , que no mês de setembro, $44 \%$ das propriedades avaliadas 
apresentaram níveis de NUP dentro dos parâmetros aceitáveis (10-16 mg/dl), 28\% em outubro e $40 \%$ em novembro. Esses dados sugerem um desequilíbrio de nutrientes na dieta em 56-72\% das propriedades nos três meses do experimento, resultante possivelmente da formulação das dietas baseadas na experiência do produtor, sem considerar as exigências nutricionais dos animais. Valores de NUP superiores a $16 \mathrm{mg} / \mathrm{dL}$ foram observados em $52 \%$ das propriedades, que podem estar associados a perdas de nitrogênio dietético, com elevação dos custos de produção.

O número de propriedades com valores de NUP abaixo de $10 \mathrm{mg} / \mathrm{dL}$ aumentou no decorrer dos meses de coleta, onde percentuais de 16, 20 e $24 \%$ foram verificados nos meses de setembro, outubro e novembro, respectivamente. Estes resultados podem ter sido influenciados pela crescente dependência de alimentos fornecidos no cocho, ocorrido a cada mês do experimento. Contudo nem sempre os produtores atendiam quantidades adequadas de alimentos no cocho, pelo fato da pouca disponibilidade de reserva de alimentos volumosos na propriedade e alto custo dos insumos para formulação de suplementos concentrados. Os valores abaixo de $10 \mathrm{mg} / \mathrm{dL}$ encontrados sugerem que as dietas eram deficientes em proteína e/ou energia. Quanto aos níveis acima dos padrões aceitáveis, estes podem estar associados ao excesso de proteína na dieta, o qual não é aproveitado pelo animal, como também pode indicar desequilíbrio ruminal entre nitrogênio e energia (VASCONCELOS et al., 2010). Segundo Oliveira et al. (2001), concentrações de NUP superiores a $19 \mathrm{mg} / \mathrm{dL}$ representam o limite para perdas de nitrogênio dietético.

$O$ teor de NUP diferiu $(\mathrm{p}<0,05)$ conforme o número de dias em lactação, sendo o teor máximo observado com 142,82 dias, demonstrado na figura 1. Isto sugere um maior consumo de alimentos ocasionado pela saída dos animais da fase do balanço energético negativo (BUTLER; ELROD, 1991) e aumento do pico de ingestão de matéria seca nesta fase, que poderia estar associada a maiores perdas de nitrogênio dietético e consequente elevação nas concentrações de NUP.

Figura 1. Determinação dos níveis de NUP (mg/dl) em função dos dias de lactação.

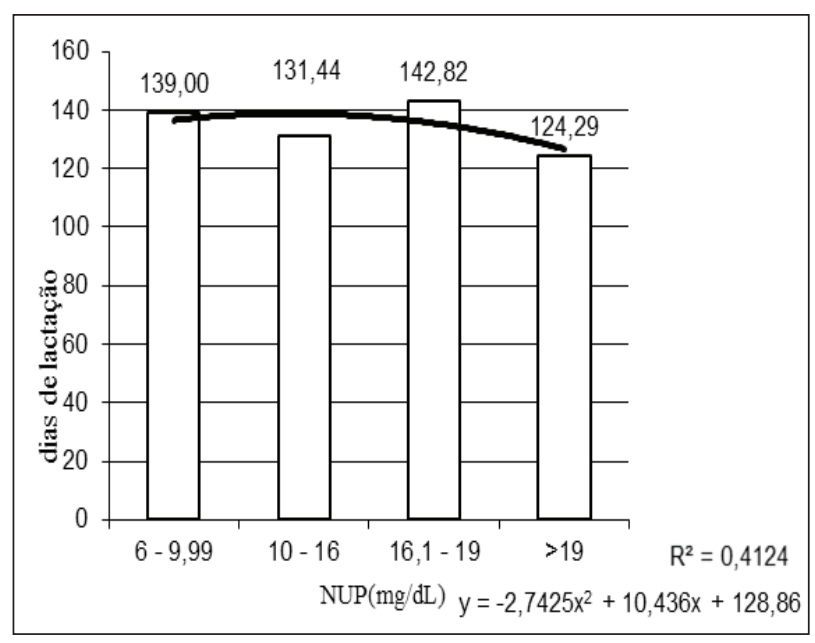

Fonte: Elaboração dos autores.

A produtividade de leite diferiu $(\mathrm{P}<0,05)$ entre os animais e houve uma tendência de elevação do
NUP nos animais com produção acima de 18,52 $\mathrm{kg}$ de leite, conforme apresentado na figura 2. Este 
resultado, pode estar associado a maior ingestão de de maior quantidade de suplementos concentrados matéria seca nesta fase da lactação e ao fornecimento aos animais de maior produção.

Figura 2. Associação entre os níveis de NUP e produção de leite (PL).

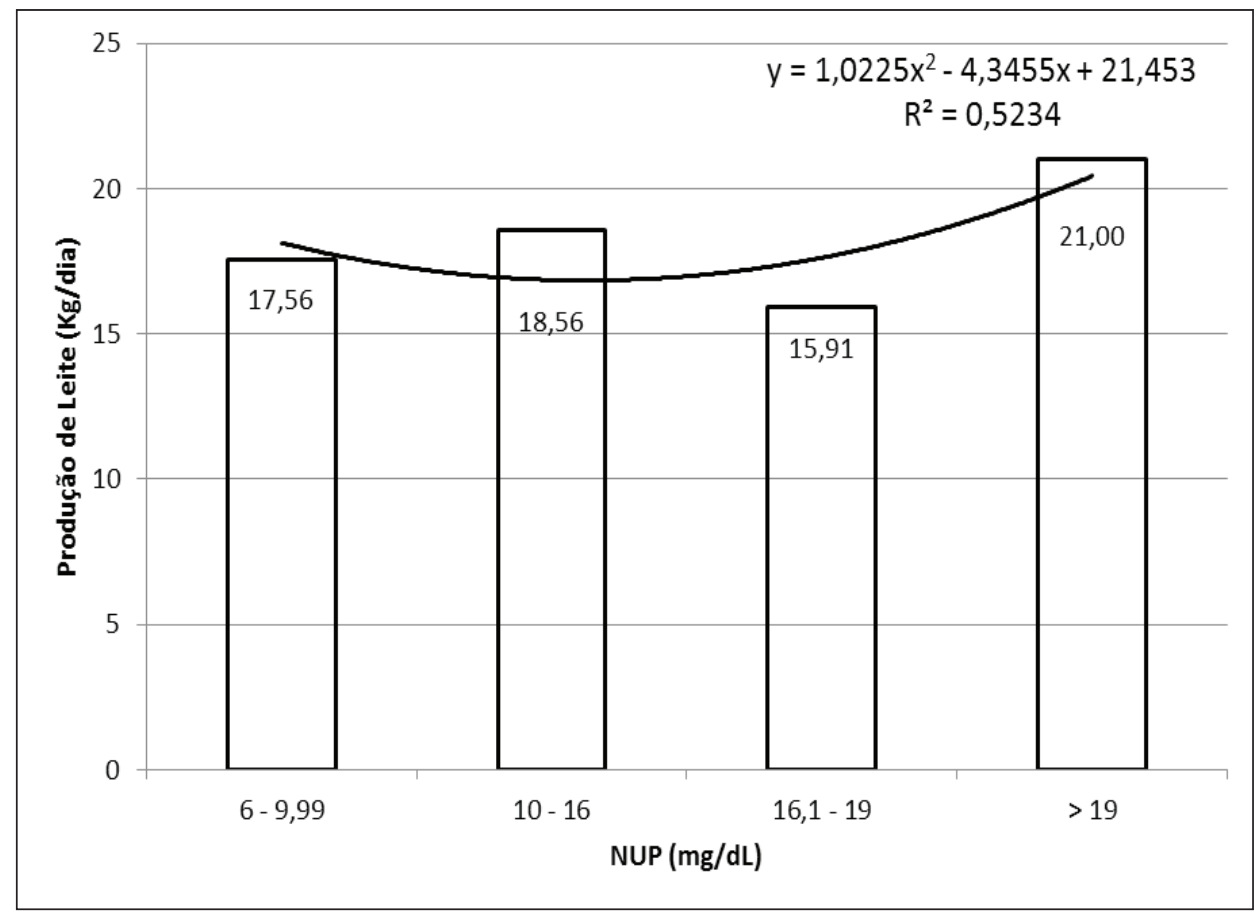

Fonte: Elaboração dos autores.

As alterações no peso e escore de condição corporal (ECC) dos animais, entre as propriedades, não foram significativas, apresentando médias de 521,2 kg e 3,08 respectivamente. O ECC observado nos animais mostrou-se dentro dos padrões desejáveis $(2,5-3,5)$ em cada período de produção.

É importante destacar a presença do alto grau de sangue holandês dos bovinos de leite criados na região, os quais são mais exigentes em condições de manejo e ambiência e mais susceptíveis a doenças, podendo resultar em perdas econômicas (OLIVEIRA; ALENCAR, 1990). A elevação dos custos de produção, com reduzido êxito econômico, foi verificada por Madalena (2001), trabalhando com raças leiteiras de origem européia no Brasil. Diante disso, o produtor deve procurar identificar, no seu rebanho, os animais que mais se adaptem as suas condições de manejo avaliando a relação custo/benefício dos mesmos em termos produtivos, reprodutivos e sanitários, lembrando que nem sempre os animais mais produtivos são os que oferecem um maior retorno financeiro. A partir daí, definir o grau de sangue mais adequado ao seu sistema de produção.

Houve diferença $(\mathrm{P}<0,05)$ em relação ao percentual de atendimento das exigências dietéticas diárias de $\mathrm{PB}$ dos animais, segundo o NRC (2001), entre as 10 propriedades (tabela 4). Foi observado que os níveis crescentes de PB na dieta influenciaram no aumento das concentrações de NUP e que a partir de $12,76 \%$ de $\mathrm{PB}$, os valores de NUP já ultrapassavam os parâmetros aceitáveis (10-16 mg/dl) (Figura 3). Estes resultados sugerem 
a necessidade de ajustes nutricionais das dietas, evitando perdas desnecessárias de nitrogênio. Jonker, Kohn e Erdman (1998) e Chizzotti, Valadares Filho e Valadares (2006) também observaram resultados associando positivamente teores dietéticos de $\mathrm{PB}$ a concentrações elevadas de NUP.

Tabela 4. Nível de NUP por propriedade e percentual de atendimento das exigências nutricionais dietéticas dos rebanhos.

\begin{tabular}{|c|c|c|c|c|c|c|c|c|c|}
\hline \multirow{2}{*}{ Propriedade } & \multirow{2}{*}{$\begin{array}{l}\text { Coleta novembro / } \\
\text { NUP }(\mathrm{mg} / \mathrm{dl})\end{array}$} & \multicolumn{8}{|c|}{ Percentual das exigências } \\
\hline & & PB (\%) & & PDR (\%) & & PNDR (\%) & & NDT $(\%)$ & \\
\hline 1 & $16,78 \mathrm{c}$ & 97,39 & $\mathrm{c}$ & 88,45 & $\mathrm{e}$ & 112,06 & $\mathrm{~b}$ & 103,63 & $\mathrm{e}$ \\
\hline 2 & $15,41 \quad \mathrm{c}$ & 75,31 & d & 73,58 & $\mathrm{f}$ & 74,38 & $\mathrm{c}$ & 99,67 & $\mathrm{f}$ \\
\hline 3 & $9,29 \mathrm{e}$ & 64,48 & d & 46,75 & $\mathrm{~g}$ & 86,68 & $\mathrm{c}$ & 101,21 & $\mathrm{f}$ \\
\hline 4 & $15,44 \mathrm{c}$ & 108,47 & $\mathrm{c}$ & 106,53 & d & 111,44 & $\mathrm{~b}$ & 115,02 & $\mathrm{a}$ \\
\hline 5 & $13,47 \mathrm{~d}$ & 75,90 & $\mathrm{~d}$ & 71,90 & $\mathrm{f}$ & 82,18 & $\mathrm{c}$ & 97,84 & $\mathrm{f}$ \\
\hline 6 & $21,68 \mathrm{~b}$ & 139,64 & $\mathrm{a}$ & 140,32 & $\mathrm{c}$ & 138,10 & $\mathrm{a}$ & 103,87 & $\mathrm{~b}$ \\
\hline 7 & $20,14 \mathrm{~b}$ & 104,97 & $\mathrm{c}$ & 179,01 & $\mathrm{~b}$ & 121,69 & $\mathrm{~b}$ & 121,60 & $\mathrm{c}$ \\
\hline 8 & 25,96 a & 120,00 & $\mathrm{~b}$ & 116,65 & $\mathrm{~d}$ & 121,32 & $\mathrm{~b}$ & 153,72 & $\mathrm{a}$ \\
\hline 9 & $13,61 \mathrm{~d}$ & 108,55 & $\mathrm{c}$ & 197,33 & $\mathrm{a}$ & 104,79 & $\mathrm{~b}$ & 112,05 & d \\
\hline 10 & 7,18 e & 67,98 & $\mathrm{~d}$ & 196,47 & $\mathrm{a}$ & 81,15 & $\mathrm{c}$ & 107,84 & $\mathrm{e}$ \\
\hline Média & 15,90 & 96,27 & & 121,70 & & 103,38 & & 111,65 & \\
\hline $\mathrm{CV}(\%)$ & 11,17 & 9,75 & & 10,63 & & 11,62 & & 4,49 & \\
\hline
\end{tabular}

*PB: proteína bruta; PDR: proteína degradável no rúmen; PNDR: proteína não degradável no rúmen; NDT: nutrientes digestíveis totais; NUP: nitrogênio ureico no plasma.

Médias seguidas de mesma letra minúscula nas colunas, não diferem entre si pelo teste de Scott Knott a 5\% de probabilidade.

Fonte: Elaboração dos autores.

Figura 3. Associação entre níveis de NUP e proteína bruta (PB), proteína degradável no rúmen (PDR) e proteína não degradável no rúmen (PNDR).

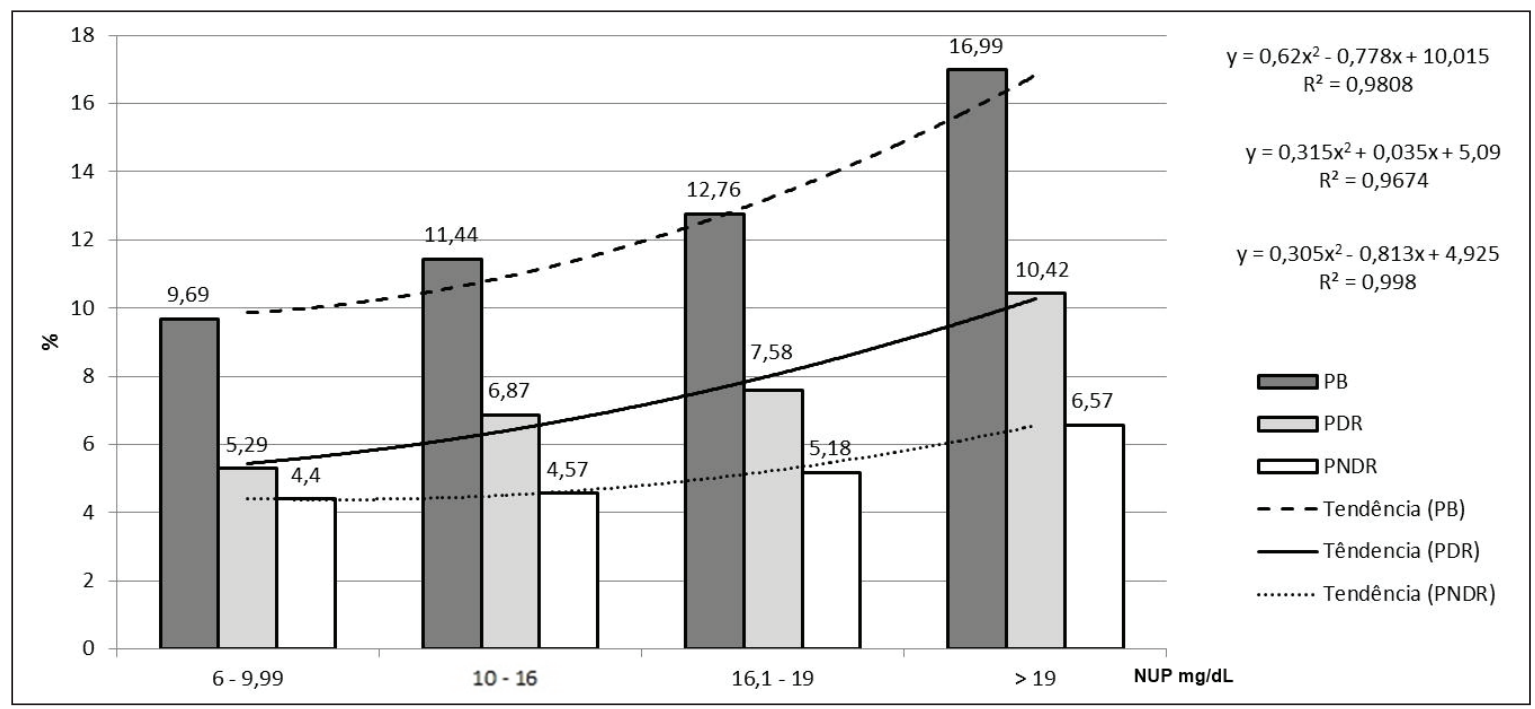

Fonte: Elaboração dos autores. 
As propriedades também diferiram $(\mathrm{P}<0,05)$ em relação aos percentuais de atendimento das exigências de PDR, PNDR e NDT, o que pode ser resultante da diversidade e quantidade de alimentos utilizados nas dietas. Além disso, foi observado que níveis crescentes de PDR e PNDR também elevaram as concentrações de NUP, porém em menor proporção, quando comparado a PB.

Nas formulações de concentrados utilizadas pelos produtores, foram verificadas grandes variações no percentual dos nutrientes entre as propriedades, que resultaram em níveis de $\mathrm{PB}$ oscilando entre 12,30 e $48,77 \%$. Essa amplitude no percentual de PB nas dietas pode gerar uma elevação no custo de produção do leite associado ao excesso de PB. Sessenta por cento das propriedades forneceram quantidades de concentrado muito próximas $(5-6 \mathrm{~kg}$ ) $\mathrm{vaca} / \mathrm{dia})$, independente do percentual de proteína no concentrado, da produção de leite e exigências nutricionais de cada animal. Este procedimento pode resultar em sobras de nutrientes, nas vacas de menor potencial produtivo, com elevação desnecessária nos custos, além de perdas de proteína dietética; e nas vacas de maior potencial produtivo, isto pode acarretar na subutilização da capacidade de produção, que implica em uma menor renda por vaca.

Alvim, Vilela e Cóser (1996), trabalhando com dois grupos de vacas por 270 dias, forneceram uma quantidade de concentrado constante $(6 \mathrm{~kg} / \mathrm{vaca} /$ dia) para um grupo e decrescente $(9,6$ e $3 \mathrm{~kg} / \mathrm{dia})$ para cada período de 3 meses, para o outro grupo. Não foram observadas diferenças na produção de leite entre os dois grupos, demonstrando que o fornecimento de concentrado deve ser ajustado pela fase de lactação e nível de produção dos animais, evitando elevação desnecessária dos custos de produção e perda de proteína dietética.

O custo do quilograma do concentrado apresentou uma variação de $\mathrm{R} \$ 0,12$ a 1,10 reais, havendo um comprometimento da renda do leite (CRL) com a aquisição do concentrado fornecido por vaca/dia, de 27,48 a $60,44 \%$, entre as propriedades (Tabela 5). Porém, na propriedade número 10, era fornecido apenas o resíduo de cervejaria para os animais, reduzindo significativamente os custos de produção e comprometendo apenas $11,78 \%$ da receita. Nessa propriedade, apesar do CRL apresentar-se inferior às demais propriedades, o atendimento das exigências nutricionais dos animais em PB foi de apenas $67,98 \%$, o que pode comprometer a produção e sanidade desses animais, se essa deficiência persistir.

Tabela 5. Comprometimento da renda do leite (CRL) com a aquisição do concentrado.

\begin{tabular}{lrrrrrrrrrr}
\hline \multicolumn{1}{c}{ Discriminação } & \multicolumn{10}{c}{ Propriedades } \\
\cline { 2 - 11 } & \multicolumn{1}{c}{01} & \multicolumn{1}{c}{02} & \multicolumn{1}{c}{03} & \multicolumn{1}{c}{04} & \multicolumn{1}{c}{05} & \multicolumn{1}{c}{06} & \multicolumn{1}{c}{08} & \multicolumn{1}{c}{09} & \multicolumn{1}{c}{10} \\
\hline Produção média leite/ vaca (kg) & 11,40 & 16,80 & 10,20 & 13,00 & 26,20 & 18,40 & 22,80 & 21,40 & 22,40 & 22,20 \\
Concentrado/vaca/dia (kg) & 5,00 & 5,00 & 5,00 & 5,00 & 6,00 & 6,00 & 15,50 & 5,00 & 14,00 & 15,00 \\
Renda do leite/vaca/dia (R\$) * & 7,98 & 11,76 & 7,14 & 9,10 & 18,34 & 12,88 & 15,96 & 14,98 & 15,68 & 15,54 \\
Custo concentrado/ kg (R\$) & 0,83 & 0,78 & 0,72 & 1,10 & 0,84 & 1,00 & 0,38 & 0,98 & 0,34 & 0,12 \\
Custo total concentrado (R\$) & 4,15 & 3,90 & 3,60 & 5,50 & 5,04 & 6,00 & 5,89 & 4,90 & 4,76 & 1,80 \\
CRL com o concentrado (\%) & 52,01 & 33,16 & 50,42 & 60,44 & 27,48 & 46,58 & 36,90 & 32,71 & 30,36 & 11,58 \\
\hline
\end{tabular}

Fonte: Produtores rurais trabalhados; CRL: Comprometimento da renda do leite

*Valor litro/leite R\$ 0,70 (mercado local, Nossa Senhora da Gloria) - Novembro/2010.

Fonte: Elaboração dos autores.

Santos et al. (2006), trabalhando com vacas leiteiras no semiárido de Pernambuco, observaram comprometimento da renda do leite entre 19 e $75 \%$, verificando que os animais que não receberam 
suplementação apresentaram, sob o ponto de vista econômico, um melhor resultado para as condições do estudo. Portanto, como a utilização de concentrados na dieta de vacas leiteiras representa o fator que mais influencia nos custos com a alimentação, torna-se importante seu uso com eficiência, para viabilizar o processo produtivo.

Em relação à reprodução, foi possível observar que a taxa de prenhez entre as propriedades variou entre 20 e $100 \%$, onde 36 vacas das 50 avaliadas, apresentaram gestação confirmada, correspondendo a $72 \%$ dos animais. Conforme mostra a tabela 6, dos animais com prenhez confirmada, 61\% encontravam-se com níveis de NUP dentro da faixa recomendada entre $10-16 \mathrm{mg} / \mathrm{dL}$ e apenas 5,56\% (dois animais) apresentavam NUP com valores superiores a $19 \mathrm{mg} / \mathrm{dl}$.

Tabela 6. Percentual de prenhez relacionado ao nível de NUP nos 10 rebanhos trabalhados.

\begin{tabular}{|c|c|c|c|c|c|c|c|c|c|}
\hline \multirow{2}{*}{$\begin{array}{l}\text { Diagnóstico de } \\
\text { gestação }\end{array}$} & \multirow[b]{2}{*}{$\begin{array}{l}\mathrm{N}^{\circ} \text { de } \\
\text { vacas }\end{array}$} & \multicolumn{2}{|c|}{$<10 \mathrm{mg} / \mathrm{dl}$} & \multicolumn{2}{|c|}{$10-16 \mathrm{mg} / \mathrm{dl}$} & \multicolumn{2}{|c|}{$>16-19 \mathrm{mg} / \mathrm{dl}$} & \multicolumn{2}{|c|}{$>19 \mathrm{mg} / \mathrm{dl}$} \\
\hline & & $\begin{array}{l}\mathrm{N}^{\circ} \text { de } \\
\text { vacas }\end{array}$ & $\%$ & $\begin{array}{l}\mathrm{N}^{0} \text { de } \\
\text { vacas }\end{array}$ & $\%$ & $\begin{array}{l}\mathrm{N}^{\circ} \text { de } \\
\text { vacas }\end{array}$ & $\%$ & $\begin{array}{l}\mathrm{N}^{0} \text { de } \\
\text { vacas }\end{array}$ & $\%$ \\
\hline Prenhez positiva & 36 & 3 & 8,33 & 22 & 61,11 & 9 & 25,00 & 2 & 5,56 \\
\hline Prenhez negativa & 14 & 1 & 7,14 & 1 & 7,14 & 1 & 7,14 & 11 & 78,58 \\
\hline Total & 50 & 4 & 8,00 & 23 & 46,00 & 10 & 20,00 & 13 & 26,00 \\
\hline
\end{tabular}

Fonte: Elaboração dos autores.

Dos 14 animais que não apresentaram prenhez, apenas três apresentaram NUP abaixo de $19 \mathrm{mg} /$ $\mathrm{dL}$ e os outros 11 animais tiveram NUP acima de desse valor em pelo menos uma coleta. Isto sugere que o elevado teor NUP nesses animais pode estar relacionado à redução das taxas de gestação das vacas nas propriedades trabalhadas. Foi verificada também, uma tendência de crescimento do período de serviço (PS), à medida que se elevaram os níveis de NUP (> $19 \mathrm{mg} / \mathrm{dL}$ ) (Figura 4).

Figura 4. Relação ao período de serviço (PS) com níveis de NUP em vacas leiteiras.

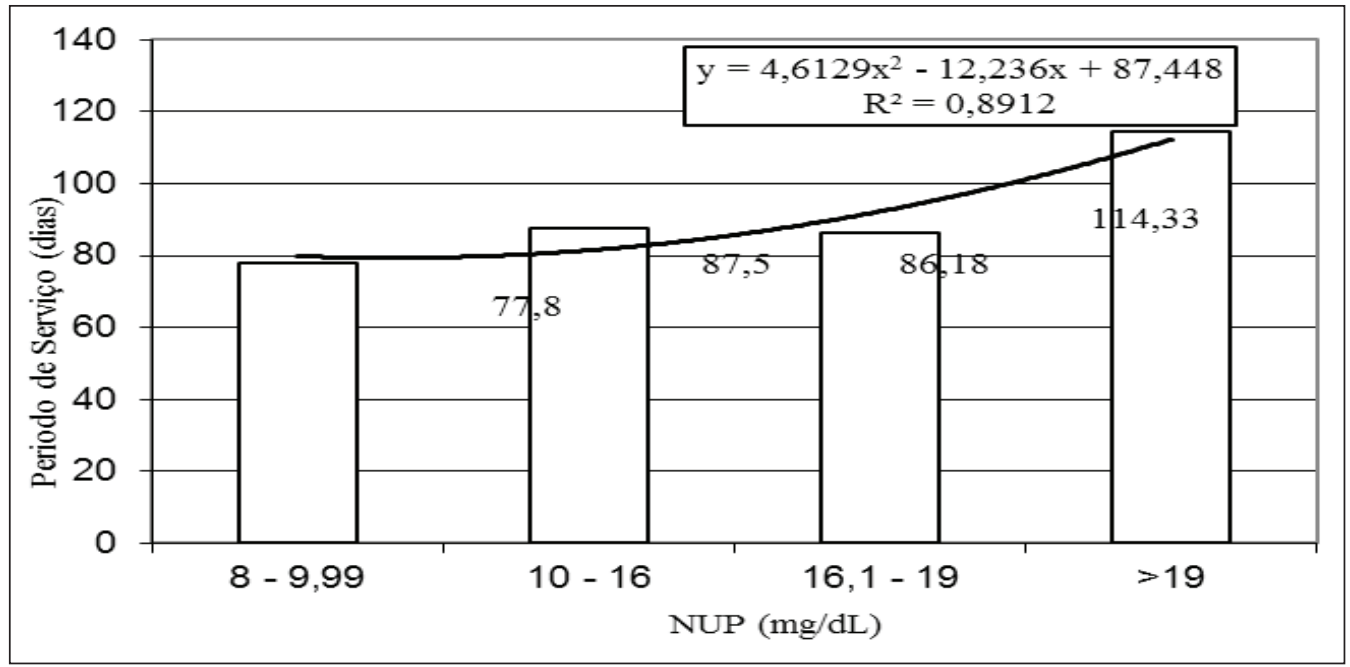

Fonte: Elaboração dos autores. 
Esses resultados sugerem que as altas concentrações de NUP encontradas nesses animais podem estar associadas a efeitos adversos de $\mathrm{N}$ no ambiente uterino, ocasionando uma redução da eficiência reprodutiva dos rebanhos e possibilitando elevação dos custos de produção. Butler (2000), observou efeitos deletérios de níveis elevados de NUP sobre o ambiente uterino na fase luteínica do ciclo estral, dificultando a manutenção da gestação, devido à redução do pH uterino. Leroy et al. (2008) comentam que a amônia e uréia provenientes do metabolismo do $\mathrm{N}$ podem ser tóxicos ao ovócito e ao embrião. Rhoads et al. (2006) verificaram que embriões coletados de vacas com concentração de NUP inferior a $19 \mathrm{mg} / \mathrm{dL}$ resultaram em taxa de gestação aproximadamente $24 \%$ maior do que embriões coletados de vacas com concentração de NUP igual ou superior a $19 \mathrm{mg} / \mathrm{dL}$.

\section{Conclusões}

Nas condições do presente estudo, os dados demonstraram grande oscilação na composição das dietas, dentro de cada propriedade, interferindo diretamente nos custos com alimentação. Houve também grande variação nos níveis de NUP que apresentaram desde valores baixos, indicando possível falha no manejo nutricional do rebanho associado à deficiência de $\mathrm{PB}$, a níveis acima dos preconizados, sugerindo um excesso de proteína oferecido aos animais ou desbalanço nutricional na relação proteína/energia. A presença de elevados teores de NUP em alguns animais provocou redução das taxas de gestação, assim como houve maiores teores de NUP nos animais com produção acima de 18,52 kg de leite. Esses dados demonstram a necessidade de uma assistência técnica local orientando para um melhor manejo nutricional desses rebanhos.

\section{Referências}

ALVIM, M. J.; VILELA, D.; CÓSER, A. C. Efeitos de dois níveis de concentrado sobre a produção de leite de vacas da raça holandesa em pastagem de coast-cross. In: REUNIÃO ANUAL DA SOCIEDADE BRASILEIRA DE ZOOTECNIA, 33., 1996. Fortaleza, CE. Anais... Fortaleza: SBZ, 1996. p. 172-173.

BERCHIELLI, T. T.; PIRES, A.V.; OLIVEIRA, S. G. Nutrição de ruminantes. Jaboticabal: Funep, 2006. 583 p.

BUTLER, W. R. Nutritional interactions with reproductive performance in dairy cattle. Animal Reprodution Science, Manchester, v. 60, n. 1, p. 449-457, 2000.

BUTLER, W. R.; CALAMAN, J. J.; BEAM, S. W. Plasma and milk urea nitrogen in relation to pregnancy in lactating dairy cattle. Journal of Animal Science, Champaign, v. 74, n. 6, p. 858-865, 1996.

BUTLER, W. R.; ELROD, C. C. Nutrition and reproduction relationships in dairy cattle. In: CORNELL NUTRITIONAL CONFERENCE, 1991, Cornell. Proceedings... Nova York: Cornell University Press, 1991. p. 73-82.

CARVALHO FILHO, O. M.; MITERNIQUE, S.; HOLANDA, J.: GERDAN, C. T. A pequena produção de leite no semiárido Sergipano. Petrolina: EMBRAPA Semiárido, 2000. 26 p.

CHIZZOTTI, M. L.; VALADARES FILHO, S. C.; VALADARES, R. F. D. Consumo, digestibilidade e excreção de uréia e derivados de purinas em novilhas de diferentes pesos. Revista Brasileira de Zootecnia, Viçosa, MG, v. 35, n. 4, p. 1813-1821, 2006.

ELROD, C. C.; BUTLER, W. R. The relationship between blood and fertility parameters in post partum dairy cows. Journal of Animal Science, Champaign, v. 71, n. 3, p. 694-701, 1993.

FERGUSON, J. D.; BLANCHARD, T.; GALLIGAN, D. T. Infertility in dairy cattle fed a high percentage of degradable of protein degradable in the rumen. Journal of the American Veterinary Medical Association, New York, v. 192, n. 5, p. 659-662, 1998.

FERREIRA, D. F. Sisvar. versão 4.2. Lavras: DEX/ UFLA, 2003. $79 \mathrm{p}$.

GOMES, F. C.; DIAS, V. C.; SOTO-BLANCO, B. Concentrações de uréia em soro e leite de bovinos do município de Mossoró, Rio Grande do Norte. Revista Ciência Animal, Santa Maria, v. 15, n. 2, p. 115-118, 2005.

HRISTOV, A. N.; ETTER, R. P.; ROPP, J. K. Effect of dietary crude protein level and degradability on ruminal fermentation and nitrogen utilization in lactating dairy cows. Journal of Animal Science, Champaign, v. 82, n. 11, p. 3219-3229, 2004.

INSTITUTO BRASILEIRO DE GEOGRAFIA E 
ESTATÍSTICA - IBGE. Produção da pecuária municipal. Rio de Janeiro: IBGE, 2010, v. 38, p. 1-65.

JONKER, J. S.; KOHN, R. A. Use of milk urea nitrogen to improve dairy cows diets. Journal of Dairy Science, Madison, v. 85, n. 4, p. 939-946, 2002.

JONKER, J. S.; KOHN, R. A.; ERDMAN, R. A. Milk urea nitrogen target concentrations for lactating dairy cows fed according to national research council recommendations. Journal of Dairy Science, Madison, v. 82, n. 6, p. 1261-1273, 1999.

Using milk urea nitrogen to predict nitrogen excretion and utilization efficiency in lactating dairy cows. Journal of Dairy Science, Madison, v. 81, n. 4, p. 2681-2692, 1998.

LEROY, J. L. M. R.; VAN SOOM, A.; OPSOMER, G.; GOOVAERTS, I. G. F.; BOLS, P. E. J. Reduced fertility in high-yielding dairy cows: are the oocyte and embryo in danger? Part II. Reproduction in Domestic Animals, Berlin, v. 43, n. 5, p. 623-632, 2008.

LUCCI, C. S.; VALVASOR, E.; PEIXOTO JUNIOR, K.; FONTOLAN,V. Concentrações de nitrogênio na dieta, no sangue e no leite de vacas lactantes no período pósparto. Revista Brasileira de Zootecnia, Viçosa, MG, v. 35, n. 1, p. 258-263, 2006.

MADALENA, F. E. Sistema de reposição contínua do rebanho leiteiro com fêmeas F1 de Bos taurus x Bos indicus no Brasil. In: MADALENA, F. E.; MATOS, L. L.; HOLANDA JUNIOR, E. V. (Org.). Produção de Leite e Sociedade. Belo Horizonte: FEPMVZ, 2001. p. 333364 ,

MERCHEN, N. R.; BOURQUIN, L. O. Processes of digestion and factors influencing digestion of forage based diets by ruminants. In: FAHEY JUNIOR, G. C. (Ed.). Forage quality, evoluation and utilization. Madison: American Society Agronomy, 1994. p. 564612.

NATIONAL RESEARCH COUNCIL - NRC. Nutrient requirement of the dairy cattle. 7. ed. Washington, D. C.: National Academy Press, 2001. 381 p.

OLIVEIRA, A. S.; VALADARES, R. F. D.; VALADARES FILHO, S. C.; CECON, P. R.; RENNÓ, L. N.; QUEIROZ, A. C.; CHIzZOTTI, M. L. Produção de proteína microbiana e estimativa das excreções de derivados de purinas e de ureia em vacas lactantes alimentadas com rações isoprotéicas contendo diferentes níveis de compostos nitrogênios não protéicos. Revista Brasileira de Zootecnia, Viçosa, MG, v. 30, n. 5, p.1621-1629, 2001.
OLIVEIRA, G. P.; ALENCAR, M. M. Resistência de bovinos de seis graus de sangue HVB: Guzerá ao carrapato (Boophilus microplus) e ao berne (Dermatobia hominis). Arquivo Brasileiro de Medicina Veterinária e Zootecnia, Belo Horizonte, v. 42, n. 2, p. 127-135,1990.

PINA, D. S.; VALADARES FILHO, S.C.; VALADARES, R. F. D.; CAMPOS, J. M. S.; DETMANN, E.; MARCONDES, M. I.; OLIVEIRA, A. S.; TEIXEIRA, R. M. A. Consumo e digestibilidade aparente total dos nutrientes, produção e composição do leite de vacas alimentadas com dietas contendo diferentes fontes de proteína Revista Brasileira de Zootecnia, Viçosa, MG, v. 35, n. 4, p. 1543-1551, 2006.

RHOADS, M. L.; RHOADS, R. P.; GILBERT, R. O.; TOOLE, R.; BUTLER, W. R. Detrimental effects of high plasma urea nitrogen levels on viability of embryos from lactating dairy cows. Animal Reproduction Science, Manchester, v. 91, n. 1, p. 1-10, 2006.

SANTOS, G. R. A.; GUIM, A.; FERREIRA, M. A.; SANTOS, M. V. F.; BATISTA, A. M. V.; LIRA, M. A.; VERAS, R. M. L. Suplementação de vacas leiteiras a pasto no período seco no sertão pernambucano. Archivos de Zootecnia, Córdoba, v. 55, n. 211, p. 239-249, 2006.

SECRETARIA DE ESTADO DO DESENVOLVIMENTO AGRÁRIO - SEAGRI. Plano de desenvolvimento do arranjo produtivo de pecuária de leite e derivados do alto sertão sergipano. Aracaju, set. 2008. 36 p. Disponível em: <http://www. desenvolvimento.gov.br/arquivos/dwnl_1247147199. pdf> Acesso: 8 maio 2012.

SISTEMA DE INFORMAÇÕES SOBRE RECURSOS HÍDRICOS DO ESTADO DE SERGIPE - SIRHSE. Elaboração do plano estadual de recursos hídricos. Relatório Síntese da Fase A. Sergipe, 2010. 72 p. Disponível em: <http//www.sirhse.semarh.se.gov.br/ sirhse//.../RFA_Relatorio_Sintese_da_Fase_A.pdf $>$. Acesso em: 8 mai. 2012.

VALADARES FILHO, S. C.; MAGALHÃES, K. A.; ROCHA JÚNIOR, V. R.; CAPELLE, E. R. Tabelas brasileiras de composição de alimentos para bovinos. Viçosa, UFV, 2006. 329 p.

VASCONCELOS, A. M.; LEÃO, M. I.; VALADARES FILHO, S. C.; VALADARES, R. F. D.; DIAS, M.; MORAES, D. A. E. F. Parâmetros ruminais, balanço de compostos nitrogenados e produção microbiana de vacas leiteiras com soja e seus subprodutos. Revista Brasileira de Zootecnia, Viçosa, MG, v. 39, n. 2, p. 425433, 2010. 
